\title{
Sub Acute Stent Thrombosis: Not an Easy Task to find out the Guilty!
}

\author{
Davide Piraino ${ }^{1}$, Pedro Leon Silva ${ }^{2}$ and Bernardo Cortese ${ }^{2 *}$ \\ ${ }^{1}$ Cardiologia Interventistica ed emodinamica, Policlinico "P.Giaccone", Palermo, Italy \\ ${ }^{2}$ Cardiologia Interventistica, A.O. Fatebenefratelli Milano, Italy
}

Received: November 07, 2014; Accepted: January 06, 2015; Published: January 10, 2015

*Corresponding author: Bernardo Cortese, Cardiologia Interventistica, A.O. Fatebenefratelli, Miano, Italy, T: +390263632896; F: +390263632210; E: bcortese@gmail.com

\begin{abstract}
Stent thrombosis is a dramatic event whose correct understaning may help its prevention. We describe the case of a very complex patient experiencing sub acute stent thrombosis of 2 overlapped drug eluting stents, whose mechanisms are incompletely understood. Current drugs (as new antiplatelet agents) and devices available (IVUS or OCT images and drug eluting stent of third generation) in our catheterization laboratories may help to better understanding and treating this sometimes catastrophic event.
\end{abstract}

Keywords: DES; Sub-acute Stent Thrombosis; Clopidogrel Resistance; Stent Underexpansion

\section{Abbreviations}

ACS: Acute Coronary Syndrome; DES: Drug-Eluting Stent; FFR: Fractional Flow Reserve; IVUS: Intravascular Ultrasound Imaging; LAD: Left Anterior Descending; PCI: Percutaneous Coronary Intervention; PRU: Platelet Response Unit; RCA: Right Coronary Artery

\section{Introduction}

Despite the clear advantages of Drug-Eluting Stents (DES) in terms of reduction of recurrent revascularizations, the increased risk of stent thrombosis is a well recognized limitation of these devices [1]. The risk of stent thrombosis is related to several factors, that depend among others on technique issues and the typology of used antiplatelet drugs.

In this case report we describe an episode of sub acute stent thrombosis in a patient with an Acute Coronary Syndrome (ACS) and 2-vessel coronary artery disease.

\section{Case Presentation}

A 67 year old indian male, hypertensive, hypercholesterolemic and with unrecognized diabetes was admitted for a 12hour persisting chest pain. The ECG showed ST elevation with QS complexes in DII-DIII-aVF, so we decided to give the patient insulin, aspirin and ticagrelor $180 \mathrm{mg}$ orally. Coronary angiography performed in urgency manner demonstrated a 2 -vessel disease consisting in 3 in sequence stenosis (one of $90 \%$ and 2 stenosis of 70\%) of a very calcific middle Left Anterior Descending Artery (LAD) and a Right Coronary Artery (RCA) suboccluded in its middle segment with high thrombus burden (Figures 1 and 2). Thus we performed a Percutaneous Coronary Intervention (PCI) with manual thrombus aspiration retrieving big red clots and subsequent implantation of a bare metal stent in the RCA. The echocardiogram showed akinesia of the basal segment and hypokinesia of the middle segment of the inferior

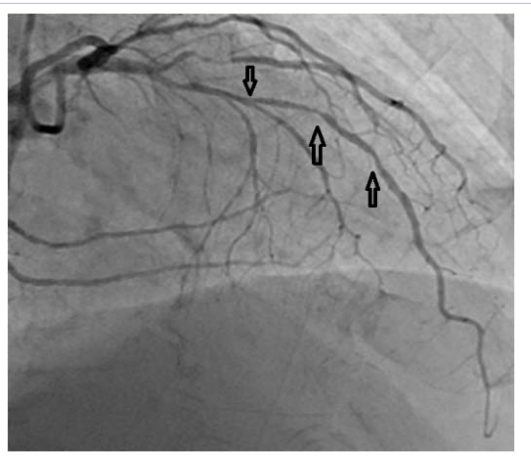

Figure 1: Diffusely Diseased Left Anterior Descending Artery at Index Procedure.

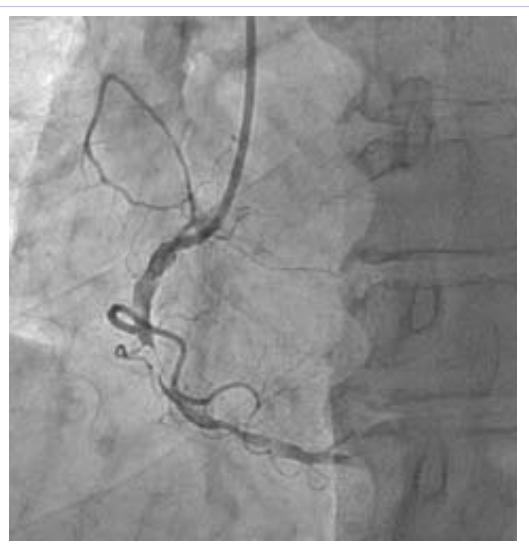

Figure 2: Occluded Right Coronary Artery with High Thrombus Burden (culprit lesion). 
wall, with preserved left ventricular ejection fraction.

Given the high risk profile of the patient, in day IV we brought him to the catheterization laboratory for a Fractional Flow Reserve (FFR)-guided PCI of middle LAD. The procedure consisted in the implantation of 2 overlapping Nobori DES $(2.5 / 28$ and $2.25 / 28 \mathrm{~mm})$ post dilated respectively with a 3.0 $\mathrm{mm}$ noncompliant balloon and a $2.5 \mathrm{~mm}$ balloon (Figure 3 ).

The patient was enrolled in the MATRIX study (an ongoing study with double randomization, bivalirudin vs unfractionated heparin, radial approach vs femoral approach), that requires an evaluation of platelet inhibition by the P2Y12 receptor. The Verify Now test performed the day after the staged FFR-guided procedure on LAD stenosis, showed an excessive platelet inhibition by ticagrelor (platelet response unit, PRU $=4$ ) [2], so according to this result and the reduced patient's compliance therapy in his country of origin (difficulty in obtaining this new antiplatelet agent), thus we switched to clopidogrel $75 \mathrm{mg} /$ day after $300 \mathrm{mg}$ oral loading dose, following the study guidelines.

At day VI, during the patient's discharge, he experienced chest pain again, at rest, with ST segment elevation in V2-V4. Immediate coronary angiography showed a sub acute ST of the middle LAD (Figure 4). We performed thrombus aspiration retrieving a big white clot and reopening the vessel, then Intravascular Ultrasound Imaging (IVUS) showed a good apposition of the DES, but with an under expansion of distal segment of the second stent in correspondence of small vessel caliber and a minimal area of 1.9 $\mathrm{mm}^{2}$ (Figure 5). The procedure finished with further prolonged stent postdilatation with $3.0 \mathrm{~mm}$ noncompliant balloons, in order to achieve an adequate minimal stent area $\left(4.7 \mathrm{~mm}^{2}\right)$ (Figures 6 and 7). Contemporarily, the Verify Now test showed clopidogrel resistance (PRU $=380)$, so we switched to ticagrerol again $(90$ $\mathrm{mg}$ bis in die).

The patient was discharged on day X, asymptomatic and with preserved left ventricular function.

\section{Discussion}

This case gives us several insights on the complex pathophysiological milieu involved in stent thrombosis. The event here described occurred in a vessel treated secondarily with FFRguided PCI. It is questionable if the LAD had to be treated before an ischemia stress test, nevertheless it is our common practice to treat the LAD if the patient is at high risk; in this case we used the FFR guidance, that has been associated to a reduction in adverse events [3].

The use of DES in coronary arteries, after an initial enthusiasm, was hampered by a supposed increased risk of stent thrombosis $[4,5]$, that taught us to correctly prepare the lesion and to post dilate the stents in order to reduce the risk of malapposition and under expansion [6]. Further studies, especially those that involved newer generation DES, showed how these devices did not carry an increased risk of stent thrombosis compared to bare metal stents [7-9].

However, the risk of stent thrombosis may have different causes [10]. Among the others there are possible genetic causes

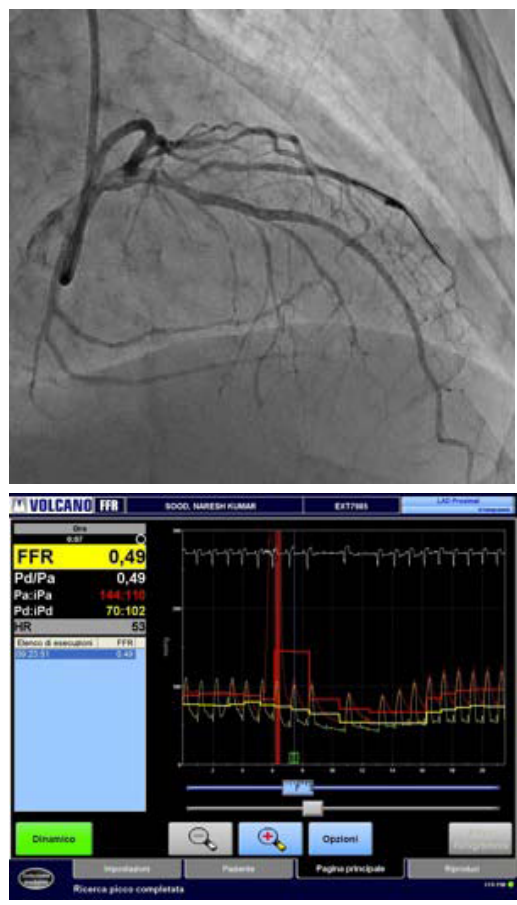

Figure 3: Fractional Flow Reserve Showing the Severy of Left Anterior Descending Artery Lesions. 3a. Final Result after Fractional Flow Reserve-Guided Angioplasty with 2 Embrocated Drug Eluting Stents at Proximal and Middle Left Anterior Descending Artery, Showing Adequate Angiographic result (day IV).

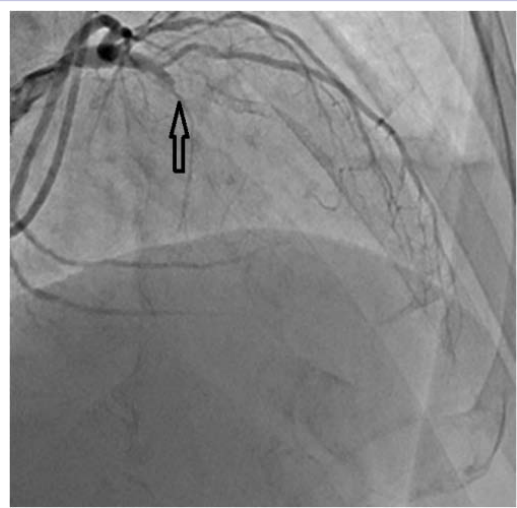

Figure 4: Complete Thrombotic Occlusion of the Left Anterior Descending Artery at Day VI.

that are incorporated in the term "clopidogrel resistance": polymorphisms that can modulate the absorption of the drug or metabolic activation (these are the most frequent mutations and involve mainly the CYP2C19 gene) or biological activity, allelic variants that are associated with an increased risk of death, heart attack and stroke [11]. Newer antiplatelet agents like ticagrelor and prasugrel have been shown to be an excellent alternative to clopidogrel and to be superior in terms of antithrombotic efficacy, contemporarily reducing the risk of drug resistance $[12,13]$.

In our case several of these aspects seemed to combine determining sub acute stent thrombosis in this patient, whose cause was probably multi factorial. The patient had a 


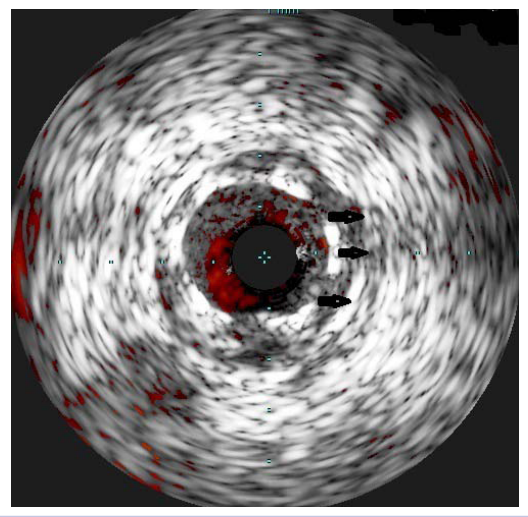

Figure 5: Intravascular Imaging, Showing a Small Vessel Area (1.9 $\mathrm{mm} 2$ ) in the Distal Part of the Second Stent, Despite Adequate Stent Apposition at the Vessel Wall.

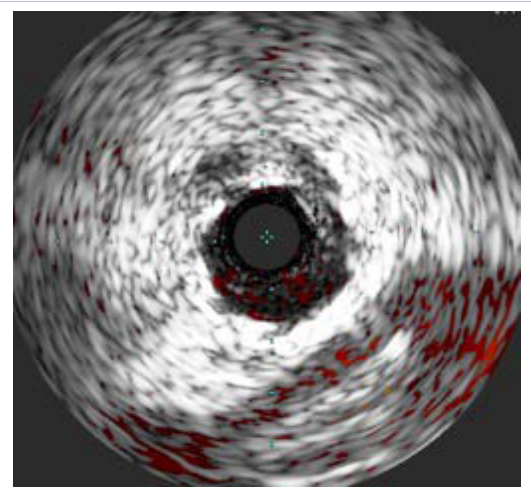

Figure 6: .Intravascular Imaging after Post dilatation, Showing Adequate Final Stent Area $\left(4.7 \mathrm{~mm}^{2}\right)$.

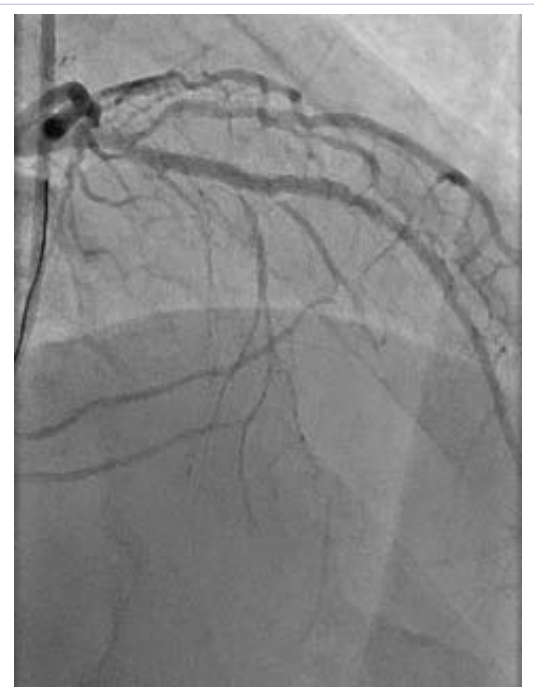

Figure 7: Final Angiographic Result after Thrombus Aspiration and Post Dilatation.

decompensated and misdiagnosed diabetes, suffered a recent ACS, had resistance to clopidogrel (as demonstrated by the Verify Now test), had 2 long and overlapped DES, and finally the distal portion of the second stent was under expanded despite a correct opposition to the vessel wall (as shown by IVUS imaging).

Clopidogrel resistance may have favored the thrombotic event, that however did not occur in the right coronary artery treated with one big bare metal stent, but involved the small caliber, calcific LAD artery treated with 2 long overlapping DES, with a final minimal area of $1.9 \mathrm{~mm}^{2}$. We hypothesize that two factors could have reduce the risk of stent thrombosis event :

1- IVUS-guidance during complex PCI might have lead to a more aggressive post dilation (IVUS not used during the FFR guided procedure on LAD, but only in occasion of stent thrombosis);

2- Avoid the switch of antiplatelet drugs from ticagrelor to clopidogrel, even if the excessive platelet inhibition by ticagrelor $(\mathrm{PRU}=4)$ and the reduced compliance to ticagrerlor therapy in his country of origin.

\section{Conclusion}

This case report provides a number of questions and considerations about the trigger of an episode of sub-acute stent thrombosis in a high risk patient. We believe that the armamentarium available in modern catheterization laboratories, e.g. more potent antiplatelet drugs and IVUS or OCT guidance, may help reducing the risk of thrombotic adverse events, even if sometimes is very difficult to find the guilty.

\section{References}

1. Cutlip DE, Baim DS, Ho KKL, Pompa JJ, Lansky AJ, Kohen DJ, et al. Stent thrombosis in the modern era. A pooled analysis of multicenter coronary stent clinical trials. Circulation 2001;103(15): 967-71.

2. Patti G, Nusca A, Mangiacapra F, Gatto L, D'Ambrosio A, Di Sciascio G. Point-of-care measurement of clopidogrel responsiveness predicts clinical outcome in patients undergoing percutaneous coronary intervention: results of the ARMYDAPRO (Antiplatelet Therapy for Reduction of Myocardial Damage during Angioplasty-Platelet Reactivity Predicts Outcome) study. J Am Coll Cardiol 2008; 52(14): 1128-33. doi: 10.1016/j.jacc.2008.06.038.

3. Li J, Elrashidi MY, Flammer AJ, Lennon RJ, Bell MR, Holmes DR, Bresnahan JF et al. Long Term Outcomes of fractional flow reserveguided vs angiography-guided percutaneous coronary intervention in contemporary practice. Eur Heart J 2013; 34(18): 1375-1383. doi: 10.1093/eurheartj/eht005.

4. Schwartz RS, Chronos NA, Virmani R. Preclinical Restenosis Models and Drug-Eluting Stents. Still Important, Still Much to Learn. J Am Coll Cardiol 2004; 44(7): 1373-85.

5. Iakovou I, Schmidt T, Bonizzoni E, Ge L, Sangiorgi GM, Stankovic G, et al. Incidence, predictors, and outcome of thrombosis after successful implantation of drug-eluting stent. JAMA 2005; 293(17): 2126-30.

6. Renata Rogacka, Azeem Latib and Antonio Colombo. IVUSGuided Stent Implantation to Improve Outcome: A Promise waiting to be fulfilled. Curr Cardiol Rev 2009; 5(2): 78-86. doi: $10.2174 / 157340309788166697$.

7. Moreno R, Fernandez C, Hernandez R, Alfonso F, Angiolillo DJ, Sabatè $M$, et al. Drug eluting stent thrombosis: results from a pooled analysis including 10 randomized studies. J Am Coll Cardiol 2005; 45(6): 9549. 
8. Ong ATL, Hoye A, Aoki J, van Mieghem CAG, Rodriguez Granillo GA, Sonnenschein K, et al. Thirty-Day Incidence and Six-Month Clinical Outcome of Thrombotic Stent Occlusion After Bare-Metal, Sirolimus, or Paclitaxel Stent Implantation. J Am Coll Cardiol. 2005; 45: 947-953. doi:10.1016/j.jacc.2004.09.079.

9. Iakovou I, Schmidt T, Bonizzoni E, Ge L, Sangiorgi GM, Stankovic G, et al. Incidence, predictors, and outcome of thrombosis after successful implantation of drug-eluting stent. JAMA 2005; 293(17): 2126-30.

10. Gill Louise Buchanan, Sandeep Basavarajaiah, Alaide Chieffo. Stent Thrombosis: Incidence, Predictors and New Technologies. Thrombosis 2012; Article ID 956962.

11. Brandt JT, Close SL, Iturria SJ, Payne CD, Farid NA, Ernest CS 2nd, et al Common polymorphismsof CYP2C19 and CYP2C9 affect the pharmacokinetic and pharmacodynamic response to clopidogrel but not prasugrel. J Thromb Haemost 2007;5(12):2429-36.

12.W. Iviott SD, Braunwald E, McCabe CH, Montalescot G, Ruzyllo W, Gottlieb S, et al. TRITON-TIMI 38 Investigators. Prasugrel versus clopidogrel in patients with acute coronary syndromes. N Engl J Med 2007; 357(20): 2001-15.

13. Wallentin L, Becker RC, Budaj A, Cannon CP, Emanuelsson H, Held C, et al. PLATO Investigators. Ticagrelor versus clopidogrel in patients with acute coronary syndromes. N Engl J Med 2009; 361(11):1045-57. doi: 10.1056/NEJMoa0904327. 